\title{
EDITORIAL
}

\section{RESILIENCE OF INFRASTRUCTURE NETWORKS}

\author{
Pathmanathan Brabhaharan', Liam M. Wotherspoon ${ }^{2}$ \\ and Rajesh P. Dhakal ${ }^{3}$
}

\section{INTRODUCTION}

Infrastructure networks are essential for the functioning of modern societies. Given our seismicity, geology and terrain, our infrastructure is particularly vulnerable to earthquakes and other natural hazards. The ability of our infrastructure to withstand earthquakes and recover quickly is paramount for the health, wellbeing and economic functionality of society.

Research and applied studies should be followed by actions in order to achieve resilient infrastructure. Sharing of the knowledge from research, assessment, strengthening and management strategies will help researchers, professionals and asset owners to pursue initiatives that enhance the resilience of our infrastructure.

This special issue focuses on recent research and practice in infrastructure resilience and makes findings available to the wider earthquake engineering community and infrastructure asset owners. This includes papers that report on recent research and practical engineering approaches to assess resilience, prioritise actions and strengthen infrastructure networks.

\section{CONTEXT}

The Wellington engineering lifelines study in New Zealand published by the Centre for Advanced Engineering in 1991 [1] carried out a high level assessment of the likely performance of Wellington's lifeline infrastructure in earthquakes, which has led to an increased focus on lifelines, such as roads, rail, water, electricity, gas, wastewater, ports and fuel supply. This study was fundamental to focussing attention onto the lifeline infrastructure networks across New Zealand. This initial study was followed by the Canterbury region lifelines study [2] which took a multi-hazard approach to considering the impact of natural hazards. These studies and other subsequent lifelines studies around New Zealand highlighted the vulnerabilities in our lifeline infrastructure systems, and the need for action. For network infrastructure, loss of life is not often a direct consequence of component damage or failure, but provision of service is important in order to support post-event recovery and minimise downtime. This led to a focus on performance, in the design of lifeline infrastructure.

Subsequent earthquake reconnaissance visits to learn from earthquakes outside of New Zealand organised and led by the New Zealand Society for Earthquake Engineering and dissemination of the findings through lecture tours around New Zealand, such as after the 1994 Kobe earthquake in Japan [3], the 2008 Wenchuan earthquake [4] and the 2016 Kumamoto earthquake [5] provided additional information on the performance of lifeline infrastructure and impetus to lifelines studies and engineering. Lifelines groups were created around
New Zealand following the examples set by Wellington and Canterbury, followed by the National Lifelines Council, which have co-ordinated the assessment and enhancement of lifeline infrastructure around New Zealand. The Civil Defence Emergency Management Act 2002 provided the legislative context and mandated authorities to assess the risk to lifelines networks and take measures to ensure that they can perform to the maximum possible extent after hazard events.

The 2010-2011 Canterbury earthquake sequence and the 2016 Kaikōura earthquake clearly demonstrated the vulnerability of lifelines infrastructure to earthquakes, with three special issues of the Bulletin that focussed on the Darfield, Christchurch and Kaikoura earthquakes highlighting the different types of infrastructure network challenges that each event created.

Developments over the past 30 years have also included assessments of resilience, development of strategies to enhance resilience and investment by asset owners to enhance the resilience of network infrastructure systems.

\section{RESILIENCE OF NETWORK INFRASTRUCTURE}

A brief synopsis of the 9 technical papers in this special issue is presented below. The papers represent a sample of research and practice from around New Zealand, and one paper on research in the United States.

Raynor and Boston [6] illustrate an approach developed to aggregate the effects of multiple hazards spatially to assess the multi-hazard exposure of the built environment to a range of natural hazards including sea level rise, storm surge, coastal erosion, tsunami, landslide and liquefaction, in the coastal city of Tauranga in New Zealand. This multi-hazard exposure assessment provided the basis for the later spatial assessment of the resilience of transport and three waters networks to multiple hazards, which itself is not covered in the paper.

Mason and Brabhaharan [7] present the impacts of the 2016 $\mathrm{M}_{\mathrm{w}}$ 7.8 Kaikoura earthquake on the State Highway and rail transportation networks, including the large earthquakeinduced landslides that cut off the transport routes for many months to over a year. The paper also presents a review of the resilience assessed for the Kaikoura coastal section of the highway in 2000 with the actual resilience observations following the earthquake in 2016, and resilience consideration during recovery operations to restore the transportation routes.

Segura et al. [8] present the application of machine learning techniques to assess the expected performance of gravity dams. They present the implementation of a polynomial response surface metamodel to emulate the response of the system and computationally and visually validating it and use to predict the continuous relative maximum base sliding of the dam in order

\footnotetext{
${ }^{1}$ Lead Guest Editor, National Technical Leader and Technical Director, Geotechnical Engineering and Resilience, WSP New Zealand, Wellington, brabha@wsp.com (Fellow).

2 Deputy Guest Editor, Associate Professor, University of Auckland, Auckland, liam.wotherspoon@auckland.ac.nz (Fellow)

${ }^{3}$ Editor-in-Chief, Bulletin of the New Zealand Society for Earthquake Engineering, rajesh.dhakal@ canterbury.ac.nz (Fellow)
} 
to build fragility functions and show the effect of modelling parameter variation. The fragility functions derived can be used to assess the seismic performance of the dam and formulate recommendations with respect to the model parameters.

Uma et al. [9] outline the compilation of water and wastewater asset data and assessment of their damage and outage for a selected earthquake scenario in Rotorua, New Zealand. They describe how they considered several nearby faults and selected the $M_{\mathrm{w}} 6$ Ngakuru Southwest Fault rupture scenario and considered the expected ground shaking and liquefaction assessment based on the geology of the area. The damage was assessed using existing fragility functions and pipeline break rate relationships developed by other researchers. The outage was assessed by considering the break rates and the likely number of crews available for repairing the damage.

Davies et al. [10] describe participatory processes used during an assessment of potential infrastructure failures and their propagation across different lifeline networks in the South Island of New Zealand, in an Alpine Fault earthquake scenario. They outline sequencing participation, and how this enabled feedback between integrated modelling and participants' impact assessment, facilitating validation and refinement of the earthquake damage modelling carried out. The paper notes the value of this participation in ensuring shared ownership of outputs and enhancing the stakeholders' understanding of the resilience issues.

Imtiaz et al. [11] present a review of research into modelling of natural hazard impacts on distributed infrastructure networks. They build on these to develop and present a framework for integrated modelling of the intra-dependencies between components within a single infrastructure network, as well as inter-dependencies between multiple infrastructure networks, to predict functionality and disruption. The paper emphasises the importance of the interfaces between the models to enable integration to assess the inter-dependencies. It illustrates this integrated modelling by applying this approach to model Wellington's electricity and water networks during an earthquake scenario, while also taking into consideration the influence of the performance of the transport network.

Sadashiva et al. [12] present the assessment of earthquake damage to nine lifeline utilities in the greater Wellington area and identification of interventions as part of the Wellington Lifelines Group resilience business case. They describe the assessment of damage and outage to the networks of roads, electricity and fuel supply in a $M_{\mathrm{w}} 7.5$ earthquake on the Wellington Fault, considering fault rupture, ground shaking, landslides, liquefaction and co-seismic subsidence. The paper also presents measures identified by the asset owners to enhance the resilience of the network, and a preferred programme developed as part of the study to invest in 25 resilience projects over a period of 20 years at an estimated cost of $\$ 3.9$ billion.

Eleni et al. [13] present a description of earthquake assessment and strengthening implemented for several heritage tunnels in Wellington's road and public transportation network. They describe the seismic performance assessment of tunnels, and of note is the cable car tunnel adjacent to a steep slope and subject to asymmetric loading. The paper describes the seismic strengthening of the road tunnels, using a combination of concrete elements formed sympathetic to the heritage values, and carefully concealed ground anchors, with double corrosion protection and post-grouting to enhance durability and resilience in earthquakes.

Brabhaharan [14] describes the first stage of an integrated land transport resilience study for the Wellington region of New Zealand, to develop a programme business case for enhancing resilience. He outlines the resilience metrics of availability and outage (then combined into a disruption state) used in the assessment of the resilience of the transport network in large earthquake and storm events, including the resilience risk posed by buildings damaged by earthquakes. The paper outlines an assessment of the relative importance of links in the transport network. The importance and disruption state are combined to assess the criticality of the transport links, to prioritise them for resilience enhancement investment.

\section{CONCLUSIONS}

The nine papers featured in this special issue present recent developments through research and practice in the past 5 years into modelling and assessing the resilience of distributed network infrastructure such as transportation, water and wastewater, electricity, gas, communications and fuel supply. They also feature the development of measures to enhance resilience, business cases and implementation with due care to preserve the heritage of associated structures. This collection of papers will be a valuable resource that can inform developments in practice, academic research and infrastructure network asset management to enhance the resilience of their lifeline assets. This would help focus and enhance future integrated research and practice, and implementation of these developments to continue to enhance the resilience of our built environment.

\section{REFERENCES}

1 CAE (1991). "Lifelines in Engineering - Wellington Case Study". Centre for Advanced Engineering (CAE), University of Canterbury, Christchurch, NZ.

2 CAE (1997). "Risks \& Realities: A Multi-disciplinary Approach to the Vulnerability of Lifelines to Natural Hazards based on the Work of the Christchurch Engineering Lifelines Group". Centre for Advanced Engineering (CAE), University of Canterbury, Christchurch. NZ, 312pp.

3 Park R, Billings, IJ, Clifton GC, Cousins J, Filiatrault A., Jennings DN, Jones LC., Perrin ND, Rooney SL, Sinclair J, Spurr DD, Tanaka H and Walker G (1995). "The HyogoKen Nanbu earthquake (the Great Hanshin Earthquake) of 17 January 1995". Bulletin of the New Zealand Society for Earthquake Engineering, 28(1): 1-98. https://doi.org/10.5459/bnzsee.28.1.1-98

4 Yu J, Yong P, Reid S, Brabhaharan P and Meng P (2009). "The Ms 8.0 Wenchuan Earthquake of 12 May 2008 reconnaissance report". Bulletin of the New Zealand Society for Earthquake Engineering, 43(1): 41-83. https://doi.org/10.5459/bnzsee.43.1.41-83

5 Chiaro G, Alexander G, Brabhaharan P, Massey C, Koseki, J, Yamada S and Aoyagi Y (2017). "Reconnaissance report on geotechnical and geological aspects of the 14-16 April 2016 Kumamoto earthquakes, Japan”. Bulletin of the New Zealand Society for Earthquake Engineering, 50(3): 365393. https://doi.org/10.5459/bnzsee.50.3.365-393

6 Raynor SC and Boston M (2021). "Multi-hazard analysis and mapping of coastal Tauranga in support of resilience planning". Bulletin of the New Zealand Society for Earthquake Engineering, 54(2): 176-183. https://doi.org/10.5459/bnzsee.54.2.176-183

7 Mason D and Brabhaharan P (2021). "Characterisation of transport resilience and measures to enhance resilience in the recovery after the 2016 Kaikoura earthquake". Bulletin of the New Zealand Society for Earthquake Engineering, 54(2): 69-81. https://doi.org/10.5459/bnzsee.54.2.69-81

8 Segura RL, Padgett JE and Paultre P (2021). "Expected seismic performance of gravity dams using machine learning techniques". Bulletin of the New Zealand Society for Earthquake Engineering, 54(2): 58-68. https://doi.org/10.5459/bnzsee.54.2.58-68 
9 Uma SR, Scheele, F, Abbott ER and Motaralla JM (2021). "Planning for resilience of water networks under earthquake hazard: A case study for Rotorua district, New Zealand". Bulletin of the New Zealand Society for Earthquake Engineering, 54(2): 135-152. https://doi.org/10.5459/bnzsee.54.2.135-152

10 Davies A, Zorn C, Wilson TM, Wotherspoon LM, Beaven S, Davies TRH and Hughes MW (2021). "Infrastructure failure propagations and recovery strategies from an Alpine Fault earthquake scenario: Establishing feedback loops between integrated modelling and participatory processes for disaster impact reduction". Bulletin of the New Zealand Society for Earthquake Engineering, 54(2): 82-96. https://doi.org/10.5459/bnzsee.54.2.82-96

11 Imtiaz SY, Uma SR, Prasanna R and Wotherspoon LM (2021). "End to end linkage structure for integrated impact assessment of infrastructure networks under natural hazards". Bulletin of the New Zealand Society for Earthquake Engineering, 54(2): 153-162. https://doi.org/10.5459/bnzsee.54.2.153-162
12 Sadashiva VK, Mowll RL, Uma SR, Lin SL, Heron DW, Horspool NA, Nayyerloo M, Williams, Syed Y, Buxton R, King AB, Lukovic B, Berryman KR and Daly MC (2021). "Improving Wellington region's resilience through integrated infrastructure resilience investments". Bulletin of the New Zealand Society for Earthquake Engineering, 54(2): 117-134.

https://doi.org/10.5459/bnzsee.54.2.117-134

13 Gkeli E, Brabhaharan P, Novakov D, Arumugam S and Mookaiya G (2021). "Strengthening heritage tunnels to enhance the resilience of Wellington's transport network". Bulletin of the New Zealand Society for Earthquake Engineering, 54(2): 97-116. https://doi.org/10.5459/bnzsee.54.2.97-116

14 Brabhaharan P (2021). "Integrated Wellington region multi-hazard land transport resilience study". Bulletin of the New Zealand Society for Earthquake Engineering, 54(2): 163-175.

https://doi.org/10.5459/bnzsee.54.2.163-175 